\title{
BMJ Open Do health literacy levels of nursing students change throughout the study programme? A cross-sectional study
}

\author{
José Rafael González-López (D) , ${ }^{1}$ María de los Angeles Rodríguez-Gázquez (i) ${ }^{2}$
}

To cite: González-López JR, Rodríguez-Gázquez MdIA. Do health literacy levels of nursing students change throughout the study programme? A crosssectional study. BMJ Open 2022;12:e047712. doi:10.1136/ bmjopen-2020-047712

- Prepublication history for this paper is available online. To view these files, please visit the journal online (http://dx.doi org/10.1136/bmjopen-2020047712).

Received 07 December 2020 Accepted 02 December 2021

Check for updates

(c) Author(s) (or their employer(s)) 2022. Re-use permitted under CC BY-NC. No commercial re-use. See rights and permissions. Published by BMJ.

${ }^{1}$ Nursing Department, Faculty of Nursing, Physiotherapy and Podiatry, Universidad de Sevilla, Seville, Spain

${ }^{2}$ Formación Básica Department, Facultad de Enfermería, Universidad de Antioquia, Medellin, Colombia

Correspondence to Dr María de los Angeles Rodríguez-Gázquez; maria.rodriguezg@udea.edu.co

\section{ABSTRACT}

Objectives The aim of this research was to analyse if the level of health literacy $(\mathrm{HL})$ of nursing students changes throughout the study programme.

Design A cross-sectional study with anonymous selfreporting was conducted.

Participants/setting 329 public university nursing students in Seville, Spain; 243 of the first year and 86 of the fourth.

Interventions The short Spanish version of the Health Literacy Survey Questionnaire-European Union was used to evaluate $\mathrm{HL}$.

Primary and secondary outcome measures The proportions of the limited level of $\mathrm{HL}$ were compared between academic years and the crude and corrected $\mathrm{OR}$ were calculated with the Mantel-Haenszel test to evaluate the effect of confusion of the sex variable on the $\mathrm{HL}$ level and academic year relationship. A logistic regression model with step-by-step analysis was run, including the independent variables sex, age, marital status, academic year and HL level (limited/sufficient) as the dependent variable.

Results $62.1 \%$ of the participants of the first year versus $47.7 \%$ of the fourth year had a limited literacy level for a crude $\mathrm{OR}$ of $1.5(95 \% \mathrm{Cl} 1.10$ to $2.21 ; \mathrm{p}=0.014)$ and a corrected by sex OR of $1.8(95 \% \mathrm{Cl} 1.10$ to 2.96 ; $\mathrm{p}=0.026)$. Only the strata in women had a statistically significant relationship. The logistic regression model ratified that the $\mathrm{HL}$ was a function exclusive to the academic year.

Conclusion The $\mathrm{HL}$ level of nursing students increases from the first to the fourth academic year, even when controlling for sex. Although the HL level in the fourth academic year was greater than that of the first, both groups had inadequate $\mathrm{HL}$ levels. It is hence recommended to implement intervention strategies, which reinforce in the curriculum the knowledge and experiences related with health communication and education to ensure that future professionals improve their $\mathrm{HL}$. Achieving adequate $\mathrm{HL}$ is crucial to be able to provide care to patients, their families and the community.

\section{INTRODUCTION}

According to Sørensen $e t a l^{1}$ health literacy (HL) 'is linked to literacy and entails people's knowledge, motivation and competences to access, understand, appraise, and apply health information in order to make judgments and

\section{Strengths and limitations of this study}

C Cross-sectional design and associations observed do not necessarily establish a cause-effect relationship.

- This is a single-centre study in 329 nursing students.

- As a strength, this research has applied the Health Literacy Survey Questionnaire-European Union questionnaire, a scale widely used in Europe.

- The main limitation is the imbalance between the number of participants in each academic year.

- The existence of gender bias in the population may be conditioning the lack of significant influence of gender on health literacy levels.

take decisions in everyday life concerning healthcare, disease prevention and health promotion to maintain or improve quality of life during the life course'. HL is intimately related to literacy in general and with the sociodemographic and economic characteristics of the population and, therefore, means a direct and significant impact on the individual and collective health of people. ${ }^{2}$

A low level of HL is among others associated with limited comprehension of health information, inefficient disease self-management, less use of preventive services, mistakes and poor compliance with treatments, increased hospital admissions and a rise in health expenditure. Therefore, a low HL is directly associated with a worse state of health. ${ }^{3-5}$

A multifactorial and multidisciplinary approach is necessary to improve the population's HL, this being considered a primordial health strategy. ${ }^{6}$ To do so, the training and sensitisation of health professionals who interact with patients is indispensable, ${ }^{7}$ with the aim of enhancing and improving the communication between them and inducing a change in health organisations and systems for HL to be included in their services. ${ }^{67}$

Nurses play a key role in providing people, families and groups in a variety of environments, with information concerning 
healthcare. ${ }^{8}$ The patient's education and effective communication are an integral part of the care, ${ }^{9}$ and the nurse must be in an optimum position to evaluate the needs of health education for people to understand and act according to the information necessary to improve their health. ${ }^{10}$ In spite of this need, nurses may lack the knowledge and skills indispensable to be effective educators, ${ }^{11}$ so we must evaluate if the future professionals are prepared, from when they are trained in universities, in order to apply the appropriate interventions. Given that women are predominant in the nursing profession ${ }^{12}$ and that they have been related with a greater HL than men, ${ }^{1314}$ this study is designed with the aim of analysing both if the level of HL of nursing students changes throughout the study programme and the effect of gender.

\section{METHODS}

A cross-sectional study was carried out. The study population was nursing students enrolled in 2019 in a public university in Seville (Spain). No sampling was done as the aim was to research all students in the first and fourth academic year groups, as this was an accessible size for data collection. Students of the first year $(n=243)$ and the fourth year $(n=86)$ were included in the research. The percentage of participation of the first year was $96.4 \%$ and that of the fourth year was $43 \%$. The non-participation was due to some students not attending class the day in which the information was collected. No student present during the information collection refused to complete the form. The exclusion criterion was not answering more than one item of the questionnaire.

\section{Data collection}

A form was used which included the variables age, sex (man and woman), marital status (single, married, separated, widowed and other type), academic course (first and fourth) and the Health Literacy Survey Questionnaire-European Union (HLS-EU-Q). To collect data, the researchers used classes which had the highest numbers of attendees in the first and fourth years. The data collection day was not notified in advance. Participants filled in the form before class. After explaining the research's aims, methodology and expected results, the students were invited to participate voluntarily in the study and they gave their consent, filling out the form themselves.

\section{Questionnaire development and content}

The short version of the Spanish HLS-EU-Q was used, ${ }^{15}$ showing 16 of the 47 items of the original questionnaire. Although answers were given on a Likert scale (1-very difficult, 2-difficult, 3-easy, and 4-very easy referring to the activities listed in the items), scores were dichotomised for the analysis: 'very difficult and difficult' $=0$ and 'easy and very easy' $=1$. The sum of the dichotomous answers of the 16 items was classified into two levels of HL: 'limited' (0-12 points) and 'sufficient' (13-16 points). ${ }^{16}$

\section{Data analysis}

The data collected was analysed using IBM SPSS Statistics for Windows, V.27.0 (IBM Corp). All variables were examined for outliers and non-normal distributions. When variables fulfilled criteria of normality, central trend and dispersion measurements were calculated. Proportions were calculated for the variables measured at the nominal or ordinal level.

The strength of association between the limited level of HL and the study variables was analysed with OR and their respective confidence intervals of $95 \%$ (95\% CI), and the relation between the two variables was verified with the $\chi^{2}$ test. Fisher test was used when an expected value was less than 5. Taking into account the possible effect of sex on the relation between academic year and the score of the short version of the Spanish HLS-EU-Q, stratification by sex was accomplished during the analysis, the OR was calculated with their respective $95 \% \mathrm{CI}$, and the OR was corrected with the Mantel-Haenszel test $\left(\mathrm{OR}_{\mathrm{M}-\mathrm{H}}\right)$.

Binary logistic regression models were performed with enter analysis, including the independent variables: age, sex, marital status and academic course. The score of the HLS-EU-Q16 was used as the dependent variable, assigning the value of 0 for those who had scores between 0 and 12 (limited literacy) and of 1 for 13-16 (sufficient literacy). Other conditions of the model were: the probability of entering the model between 0.05 and 0.10 , the classification table had a cut-off point of 0.5 and a maximum of 20 interactions to examine, and the statistical significance of the parameters estimated was interpreted in accordance with a value of 0.05 . The Hosmer-Lemeshow test was used to assess the goodness of fit for the model.

\section{Patient and public involvement}

Neither the participants nor the public participated in the study design.

\section{RESULTS}

Cronbach's alpha was 0.78 for the total number of the participants, 0.75 for those of the first year, and 0.82 for those of the fourth; these values are considered appropriate. ${ }^{17}$ In case an item was not answered, it was replaced with the mean of each item, the criterion being that it was a question of an arbitrary pattern. ${ }^{18}$ Twenty-nine questionnaires were not considered as students failed to provide answer in one item.

As shown in table 1, participants in both courses of this study were predominantly woman and single, but there was a significant difference by age, with 20.1 years in the first academic year and 22.1 years in the fourth year $(\mathrm{p}<0.001)$.

Analysing the HLS-EU-Q16 score, it is also noted that there are statistically significant differences for the mean of the total score between the first and fourth year (11.8 vs $12.6 ; \mathrm{p}=0.018$ ), and in the items of the questionnaire: I02 'Check where to get professional help when you are ill' $(\mathrm{p}=0.039), \mathrm{I} 03$ 'Understand what the doctor says' 
Table 1 General characteristics of the participants and mean values of the total Health Literacy Survey QuestionnaireEuropean Union (HLS-EU-Q16) and for each item according to the academic year

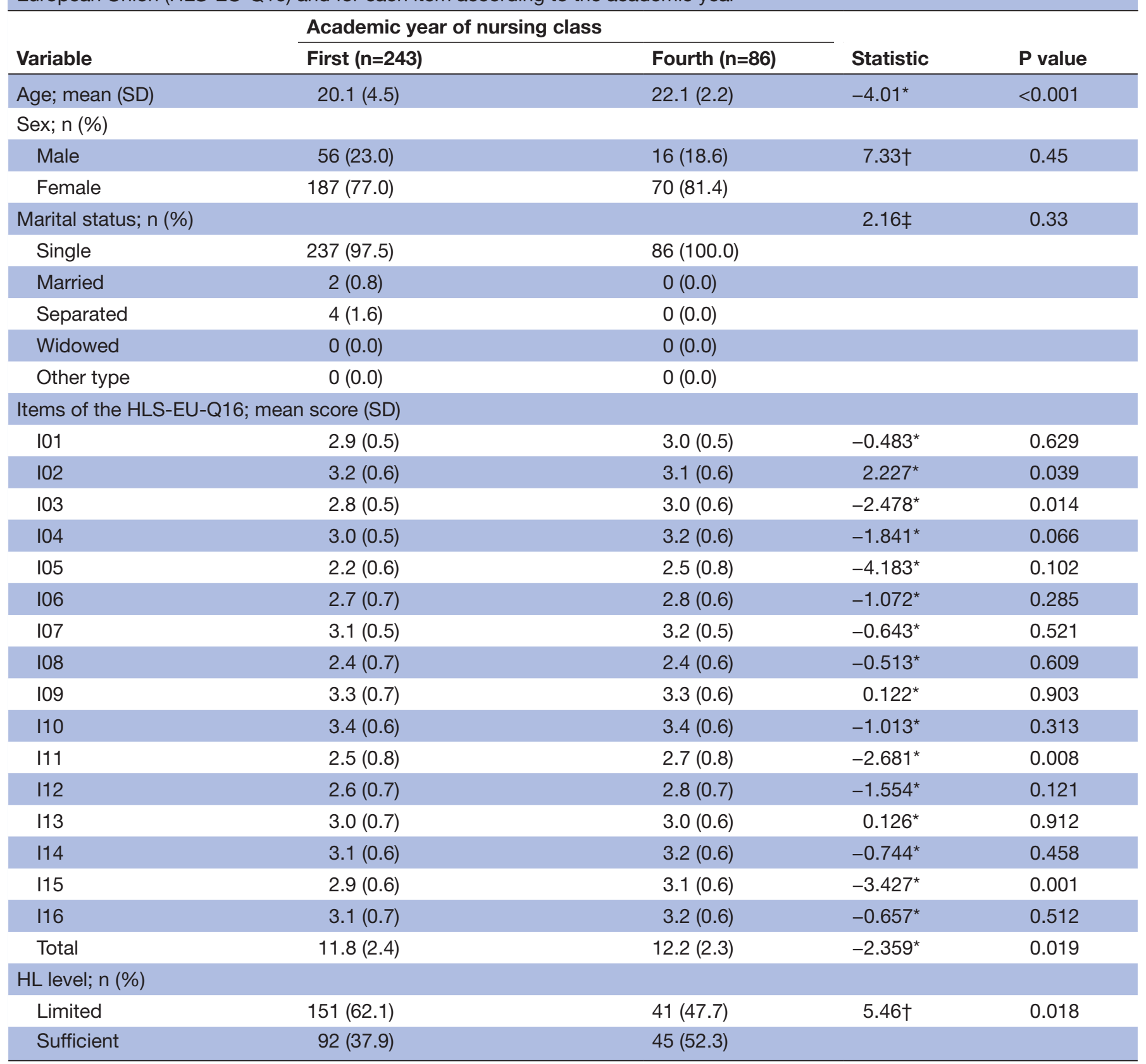

*Student's t-test.

†Pearson's $\chi^{2}$.

¥Fisher's exact test.

$\mathrm{HL}$, health literacy.

$(p=0.014)$, I11 'Value the reliability of the information about risks for health that appear in the media' $(p=0.008)$, and in $\mathrm{I} 15$ 'Understand the information provided by the media about how to improve your health' $(p=0.011)$. With the exception of item I02, for the previous associations the score was higher in the students of the fourth year than in those of the first year.

The items with the lowest score were I05 'Value when a second opinion of another doctor may be needed', I08 'Find information about how to deal with mental health problems, such as stress or depression', and I11 'Value the reliability of the information about risks for health that appear in the media', although the difference in I11 was the only one that was statistically significant.

When the association between the course and the literacy level is revised, it is observed that $62.1 \%$ of the participants of the first course versus $47.7 \%$ of the fourth course have a limited HL level, for a crude OR of 1.5 ( $(95 \%$ CI 1.10 to 2.21$) ; \mathrm{p}=0.018)$. When this is stratified by sex, it is found that the strength of the association 
Table 2 OR and $95 \% \mathrm{Cl}$ of the OR by academic year (first/fourth) stratified by sex according to Health Literacy Survey Questionnaire-European Union (HLS-EU-Q16) items according to the difficulty to carry out the activities of HL

\begin{tabular}{|c|c|c|c|}
\hline \multirow[b]{2}{*}{ Items } & \multicolumn{2}{|l|}{ Sex } & \multirow[b]{2}{*}{ Total $(95 \% \mathrm{Cl})$} \\
\hline & Male $(95 \% \mathrm{Cl})$ & Female $(95 \% \mathrm{Cl})$ & \\
\hline 101 & 1.52 (0.29 to 7.78$)$ & 1.1 (0.52 to 2.33 ) & 1.17 (0.59 to 2.31$)$ \\
\hline 102 & 1.47 (0.15 to 13.5$)$ & $0.3(0.12 \text { to } 0.75)^{\star \star}$ & $0.41(0.18 \text { to } 0.91)^{*}$ \\
\hline 103 & $1.52(0.29$ to 7.7$)$ & 1.81 (0.90 to 3.50$)$ & 1.72 (0.91 to 3.27$)$ \\
\hline 104 & 0.54 (0.08 to 3.25$)$ & 0.86 (0.37 to 1.97$)$ & 0.78 (0.37 to 1.13$)$ \\
\hline 105 & $1.13(0.34$ to 3.79$)$ & $2.58(1.44 \text { to } 4.64)^{\star \star}$ & $2.18(1.29 \text { to } 3.68)^{\star \star}$ \\
\hline 106 & 0.73 (0.21 to 2.47$)$ & $1.53(0.84$ to 2.77$)$ & 1.31 (0.76 to 2.24$)$ \\
\hline 107 & 3.52 (0.18 to 67.18$)$ & 0.83 (0.24 to 2.81) & 1.25 (0.40 to 3.91$)$ \\
\hline 108 & 0.83 (0.27 to 2.55$)$ & 1.17 (0.67 to 2.04$)$ & 1.08 (0.65 to 1.77$)$ \\
\hline 109 & 3.26 (0.38 to 27.62$)$ & 0.90 (0.35 to 2.27$)$ & 1.21 (0.53 to 2.79$)$ \\
\hline 110 & $2.14(0.24$ to 18.83$)$ & 1.39 (0.37 to 5.51$)$ & 1.64 (0.53 to 4.958$)$ \\
\hline 111 & 0.72 (0.24 to 2.21) & $2.57(1.43 \text { to } 4.61)^{\star \star}$ & $1.97(1.18 \text { to } 3.29)^{\star *}$ \\
\hline 112 & 1.65 (0.51 to 5.38$)$ & 0.99 (0.57 to 1.75$)$ & 1.10 (0.66 to 1.83$)$ \\
\hline 113 & 0.61 (0.14 to 2.73$)$ & 1.12 (0.56 to 2.21$)$ & 0.99 (0.53 to 1.85$)$ \\
\hline 114 & 3.23 (0.38 to 27.62$)$ & $0.93(0.34$ to 2.50$)$ & 1.29 (0.53 to 3.11$)$ \\
\hline 115 & $1.47(1.21 \text { to } 1.78)^{\star *}$ & 1.28 (0.59 to 2.77$)$ & $2.22(1.07 \text { to } 4.59)^{\star}$ \\
\hline 116 & $0.78(0.68 \text { to } 0.90)^{*}$ & 1.51 (0.68 to 3.32$)$ & 1.99 (0.93 to 4.27$)$ \\
\hline
\end{tabular}

Significance level: ${ }^{*} p$ value $<0.05,{ }^{\star \star} p$ value $<0.01$.

between literacy level and the course $\left(\mathrm{OR}_{\mathrm{M}-\mathrm{H}}=1.80(1.10-\right.$ $2.969) ; \mathrm{p}=0.026$ ) was slightly reduced from 1.8 to 1.5 . Also, the relationship of the HL and the course was only significant in the women strata.

An equal effect of confusion for the sex variable was noted in five of the 16 items. The OR indicated a greater risk of difficulty to carry out the activities of HL in students of the first course when they were compared with those of the fourth year in the items I05 'Value when a second opinion of another doctor may be needed' (for the total and in women; $\mathrm{p}=0.003$ and $\mathrm{p}=0.001$, respectively), I11 'Value the reliability of the information about risks for health that appear in the media' (for the total and in women; $\mathrm{p}=0.006$ and $\mathrm{p}=0.001$, respectively), and I15 'Understand the information provided by the media about how to improve your health' (for the total and in men; $\mathrm{p}=0.017$ and $\mathrm{p}=0.001$, respectively). On the other hand, a greater risk of difficulty to carry out the activities of HL was found in the students of the fourth year compared with those in the first in item I02 'Check where to get professional help when you are ill' (for the total and in women; $\mathrm{p}=0.025$ and $\mathrm{p}=0.010$, respectively), and in I16 'Value which of your daily habits affect your health' (for men; $p=0.036$, respectively). See table 2 .

As it was noted in the model, HL was exclusively explained by academic year variable (table 3 ) and the students of the first year had a $22 \%$ risk excess for a limited HL compared with those of the fourth year (table 4).

The logistic regression showed an accuracy of $60.5 \%$ and a general moderated agreement for classifying the subject correctly into limited or sufficient HL, showing better results in the classification of subjects with a limited HL $(77.8 \%)$ than in those with a sufficient HL $(37.0 \%)$ (table 5). The result of the Hosmer-Lemeshow test was $\mathrm{p}=0.61 \quad\left(\chi^{2}=5.35, \mathrm{df}=7\right)$, which indicated that the logistic regression model had a good fit.

\section{DISCUSSION}

This study, which examined the HL level of nursing students in the first and fourth academic years at the University of Seville, showed that the HLS-EU-Q16 score was higher in the fourth year than in the first (11.8 vs 12.6, $\mathrm{p}<0.05)$, a finding that was corroborated in the logistic regression, where HL was positively related to the academic year. This is consistent with other researchers conducted with nursing students in the USA, ${ }^{19}$ Turkey ${ }^{2021}$ and Jordan, ${ }^{22}$ in which it was noted that

Table 3 Initial binary logistic regression for limited health literacy as dependent variable and sociodemographic indicators as predictors

\begin{tabular}{lllrl} 
& & $95 \% \mathbf{C l}$ & \\
Variable & OR & Lower & Upper & P value \\
\hline Constant & 0.20 & & & $<0.001$ \\
Age & 1.01 & 0.93 & 1.10 & 0.771 \\
Sex & 0.93 & 0.54 & 1.60 & 0.797 \\
Marital status & 2.14 & 0.37 & 12.38 & 0.395 \\
Academic year & 1.22 & 1.02 & 1.46 & 0.031 \\
\hline
\end{tabular}


Table 4 Final binary logistic regression for limited health literacy as dependent variable and academic year course as predictor

\begin{tabular}{lllll}
\hline & & \multicolumn{2}{c}{$\mathbf{9 5 \% \mathbf { C l }}$} & \\
\cline { 3 - 4 } Variable & OR & Lower & Upper & P value \\
\hline Constant & 0.19 & & & $<0.001$ \\
Academic year & 1.22 & 1.03 & 1.44 & 0.020 \\
\hline
\end{tabular}

the HL level increased as students advanced in the study plan and they were exposed to clinical and community practices in which they learn to provide care and experience that individuals' health education is a subject of vital importance. ${ }^{5}$

What is certain is that the experience acquired by nursing students during their formative years is associated with an improvement in their health knowledge. ${ }^{23}$ If universities focus on HL in their curricula, future nurses will undoubtedly have more opportunities to improve and apply their health knowledge. ${ }^{24}$

The proportion of students with a limited HL level in this study was $62.1 \%$ in the first academic year and $47.7 \%$ in the fourth. The result obtained for the first year in this study was very similar to the $58.3 \%$ of the Spanish general population (measured with the HLS-EU-Q47). ${ }^{13}$ Regarding other researches with nursing students which have also used the HLS-EU-Q16, the percentage of limited HL obtained in both academic years of our study is higher than that reported in Turkish students $(29 \%)^{25}$ and in students of the fourth university academic year of a study in Spain and France $(30.2 \%) .{ }^{26}$

Similar to findings of the studies ${ }^{26}$ in Spanish and French universities, students of the first and fourth academic year had the lowest score in the items I05 'Value when a second opinion of another doctor may be needed', I08 'Find information about how to deal with mental health problems, such as stress or depression' and I11 'Value the reliability of the information about risks for health that appear in the media'. These results must be taken into account to reinforce in study plans the topics related to searching for information with a due evaluation of truthfulness and quality. Here the important role played by the Internet in this area should also be highlighted, as it is used by the majority of the population as a tool to obtain information about health topics. ${ }^{27}$ Notwithstanding, it should be noted that there is a considerable amount of misinformation circulating on the internet, so HL is particularly important in educating people with limited capacity to assess the accuracy of this information, ${ }^{28}$ particularly considering than some people prefer accessing health information through the Internet rather than asking their healthcare provider. ${ }^{29}$

In our study, the association between the academic year and the HL level was affected by sex.

This relationship was higher and significant for the strata of women, although in the individual analysis there was not a difference by sex in 12 of the 16 items. In other studies, there have been diverse results. While differences by sex were not found in Turkish nursing students, ${ }^{20}$ research in Jordan ${ }^{22}$ reported better levels of HL in women in some areas which are related with the capacity to find information and how to understand health information. Our study coincided with women being better at seeking information, but men excelled them in tasks of understanding the information that they obtained. Finally, in a Chinese study, ${ }^{30}$ it was found that the capacity to obtain, evaluate and understand information in nursing students is not different by sex.

On the relationship between sex and HL, Aldin $e t a l^{31}$ point out that there is a lack of consensus in previous research. While some researchers found a non-significant effect, others suggest that women present a higher level of HL than men. Thus, they ${ }^{31}$ explain the existence of different result by the existence of specific factors-such as culture or religion-that may be influencing this relationship. These authors ${ }^{31}$ state that men and women have differences in the needs for information on specific health risks, which would affect how it is accessed, understood, evaluated and, in the end, converted into healthpromoting behaviour. In this sense, we consider that our findings may favour strategies based on active formative methodology (problem-based learning or flipped classroom) to students at the beginning of their formative period.

In our research, HL levels found in nursing students were limited in the case of first and fourth year students. ${ }^{16}$ Various authors ${ }^{2421}$ have pointed out that it is necessary to develop specific training in the programme's curriculum combining increasing nursing students HL level and the development of communicative skills to patients in order to enhance HL levels among the general population. This is crucial as it is a question of preparing students to cope with the challenges of providing nursing care in the clinical or community environments, where they

Table 5 Model binary logistic regression for health literacy level at cut off $=0.5$

\section{Predicted}

Level of health literacy

Observed

Limited

Level of health literacy

Limited

147

Sufficient

Percentage correct

Sufficient

85

42

77.8

37.0

Accuracy per cent

60.8 
must identify the people who have a limited knowledge concerning health and be able to adapt the information for them, so these people have a better understanding regarding health information, while improving their selfcare capacity. ${ }^{532}$

Lastly, both individuals and communities must actively engage in the HL process, changing their attitudes and expectations with respect to the traditional model, and getting involved with professional teams, debates and decision-making forums, where future nursing professionals must play an important role in this process. Here, HL mat put forward unique opportunities to guide healthcare and suggest solutions for problems in the health system. ${ }^{33}$ This would open a scenario where more diverse health services could thrive and communities' empowerment $\mathrm{o}$ will then be achieved, guaranteeing people a greater control concerning their state of health and well-being. ${ }^{34}$

The conclusion of this study is that the HL level in nursing students increases from the first to the fourth academic year. However, although HL level in the fourth year was higher than that in the first year, its was not satisfactory either. Hence, it is recommended to implement intervention strategies that reinforce the curriculum with specific training which combine increasing nursing students HL level and the development of communicative skills, in an effort to ensure that future professionals manage an adequate level of HL to be able to provide care to patients, their families and the community.

\section{Limitations of the study}

This study has some limitations. First, the information was obtained by self-reporting and could not be verified by other means, although we believe that the anonymity favoured honest answers to the questionnaire. Second, one limitation is that the study design was cross-sectional, and therefore associations observed do not necessarily establish a cause-effect relationship. Third, there is an imbalance between the number of participants by group (more in the first than in the fourth year) and by sex (more women than men). Therefore, stratified analyses were carried out to control for the confusion effect of gender. Finally, other variables-same level of education, socioeconomic level, presence of work activity, health habits-were not considered in this study. These aspects will be dealt with in further research.

Acknowledgements The authors thank those individuals who participated in the survey and particularly Ana Ruiz-Iglesias for her research assistance.

Contributors Both authors contributed to the study design and conduct of the study. JRG-L was responsible for the data collection and management. Both authors performed the statistical analyses, were involved in the preparation of the manuscript and reviewed or approved the manuscript. MAR-G acts as a guarantor.

Funding The authors have not declared a specific grant for this research from any funding agency in the public, commercial or not-for-profit sectors.

Competing interests None declared.

Patient and public involvement Patients and/or the public were not involved in the design, or conduct, or reporting, or dissemination plans of this research.

Patient consent for publication Not applicable.
Ethics approval Administrative and ethical approval for the study were obtained from the Faculty of Nursing, Physiotherapy and Podiatry at the University of Seville prior to contacting potential participants. The approval does not have a number associated (document signed by Faculty is attached such as supplementary material for Editors only). Participants gave informed consent to participate in the study before taking part.

Provenance and peer review Not commissioned; externally peer reviewed.

Data availability statement Data are available upon reasonable request. The data are available from María de los Ángeles Rodríguez-Gázquez (email: maria. rodriguezg@udea.edu.co).

Open access This is an open access article distributed in accordance with the Creative Commons Attribution Non Commercial (CC BY-NC 4.0) license, which permits others to distribute, remix, adapt, build upon this work non-commercially, and license their derivative works on different terms, provided the original work is properly cited, appropriate credit is given, any changes made indicated, and the use is non-commercial. See: http://creativecommons.org/licenses/by-nc/4.0/.

\section{ORCID iDs}

José Rafael González-López http://orcid.org/0000-0002-8962-3540

María de los Angeles Rodríguez-Gázquez http://orcid.org/0000-0002-4329-4286

\section{REFERENCES}

1 Sørensen K, Van den Broucke S, Fullam J, et al. Health literacy and public health: a systematic review and integration of definitions and models. BMC Public Health 2012;12:80.

2 Parnell P. Health literacy in nursing: providing person-centered care. Springer Publishing Company, 2015.

3 Haun JN, Patel NR, French DD, et al. Association between health literacy and medical care costs in an integrated healthcare system: a regional population based study. BMC Health Serv Res 2015;15:249.

4 Balmer D, King A, Moloney W, et al. Nursing students and health literacy: the effect of region and programme level. Nurse Educ Pract 2020;42:102688.

5 McCleary-Jones V. A systematic review of the literature on health literacy in nursing education. Nurse Educ 2016;41:93-7.

6 Juviny -Canal D, Bertran-Noguer C, Suñer-Soler R. más que información. Gac Sanit 2018;32:8-10.

7 Sørensen K, Karuranga S, Denysiuk E, et al. Health literacy and social change: exploring networks and interests groups shaping the rising global health literacy movement. Glob Health Promot 2018;25:89-92.

8 Loan LA, Parnell TA, Stichler JF, et al. Call for action: nurses must play a critical role to enhance health literacy. Nurs Outlook 2018;66:97-100.

9 Dickens C, Lambert BL, Cromwell T, et al. Nurse overestimation of patients' health literacy. $J$ Health Commun 2013;18 Suppl 1:62-9.

10 Speros $\mathrm{Cl}$. Promoting health literacy: a nursing imperative. Nurs Clin North Am 2011;46:321-33.

11 Reynolds L, Attenborough J, Halse J. Nurses as educators: creating teachable moments in practice. . Nursing Times, 2020: 116. 25-8.

12 Christensen M. Men in nursing: the early years. J Nurs Educ Pract 2017;7:94-103.

13 Sørensen K, Pelikan JM, Röthlin F, et al. Health literacy in Europe: comparative results of the European health literacy survey (HLS-EU). Eur J Public Health 2015;25:1053-8.

14 Baker P. Men's health: an overlooked inequality. Br J Nurs 2016;25:1054-7.

15 Sørensen K, Van den Broucke S, Pelikan JM, et al. Measuring health literacy in populations: illuminating the design and development process of the European health literacy survey questionnaire (HLSEU-Q). BMC Public Health 2013;13:948.

16 Nolasco A, Barona C, Tamayo-Fonseca N, et al. [Health literacy: psychometric behaviour of the HLS-EU-Q16 questionnaire]. Gac Sanit 2020;34:399-402.

17 Tavakol M. The reliability of assessments: The bayesian cronbach's alpha. Med Teach 2017;39:567.

18 Enders C, Bandalos D. The relative performance of full information maximum likelihood estimation for missing data in structural equation models. Structural Equation Modeling: A Multidisciplinary J. 2001;8:430-57.

19 Williamson S, Chopak-Foss J. Differences in health literacy knowledge and experiences among senior nursing students. $J$ Georgia Public Health Assoc 2015;5:184-90.

20 Ayaz-Alkaya S, Terzi H, Handan T. Investigation of health literacy and affecting factors of nursing students. Nurse Educ Pract 2019;34:31-5. 
21 Erunal M, Ozkaya B, Mert H. Investigation of health literacy levels of nursing students and affecting factors. Int J Caring Sci 2018;11:1386.

22 Rababah JA, Al-Hammouri MM, Drew BL, et al. Health literacy: exploring disparities among college students. BMC Public Health 2019;19:1401.

23 Holt KA, Overgaard D, Engel LV, et al. Health literacy, digital literacy and eHealth literacy in Danish nursing students at entry and graduate level: a cross sectional study. BMC Nurs 2020;19:22.

24 Koduah AO, Amoah PA, Nkansah JO, et al. A comparative analysis of student and practising nurses' health literacy knowledge in Ghana. Healthcare 2021;9:38.

25 Ozen N, Bal Ozkaptan B, Coskun S, et al. Health literacy of nursing students and its effective factors. Nurs Forum 2019;54:396-402.

26 Juvinyà-Canal D, Suñer-Soler R, Boixadós Porquet A, et al. Health literacy among health and social care university students. Int $J$ Environ Res Public Health 2020;17:2273.

27 Diviani N, Fredriksen EH, Meppelink CS, et al. Where else would look for it? A five-country qualitative study on purposes, strategies, and consequences of online health information seeking. J Public Health Res 2019;8:1518.
28 Rolls K, Massey D. Social media is a source of health-related misinformation. Evid Based Nurs 2021;24:46.

29 Oedekoven M, Herrmann WJ, Ernsting C, et al. Patients' health literacy in relation to the preference for a general practitioner as the source of health information. BMC Fam Pract 2019;20:94.

30 Zou M, Zhang Y, Zhang F, et al. The ability to obtain, appraise and understand health information among undergraduate nursing students in a medical university in Chongqing, China. Nurs Open 2018;5:384-92.

31 Aldin A, Chakraverty D, Baumeister A, et al. Gender differences in health literacy of migrants: a synthesis of qualitative evidence. Cochrane Database Syst Rev 2019;5.

32 Kaas J, Stasková V, Šulistová R. The concept of health literacy in contemporary nursing. Kontakt 2016;18:e219-23.

33 Heuser C, Diekmann A, Kowalski C, et al. Health literacy and patient participation in multidisciplinary tumor conferences in breast cancer care: a multilevel modeling approach. BMC Cancer 2019;19:330.

34 Muscat DM, Shepherd HL, Nutbeam D, et al. Health literacy and shared decision-making: exploring the relationship to enable meaningful patient engagement in healthcare. J Gen Intern Med 2021;36:521-4. 